\title{
A arte para além do belo: considerações psicanalíticas
}

\author{
Wagner Siqueira Bernardes*
}

\begin{abstract}
Resumo
Neste trabalho serão abordadas algumas formulações de Sigmund Freud sobre a estética e a arte. A partir da estética, concebida como ciência do belo e doutrina das qualidades de nosso sentir, Freud envereda por uma trilha marginal destacada por ele como "o estranho". Este tema, devido a seu caráter sinistro, provoca medo, repulsa e, até mesmo, horror. Entretanto, pode ser um recurso utilizado pelo artista para despertar sentimentos contrários. A encenação trágica assim o demonstra pois, ao induzir no espectador as mais dolorosas impressões, proporciona-lhe, ao mesmo tempo, a fruição de emoções altamente prazerosas. Se, em princípio, o ser humano é regido pela busca do prazer e evitação do desprazer resta compreender como a dor pode se tornar veículo e condição de deleite.

Palavras-chave: Sigmund Freud. Estética. Arte. Estranho.
\end{abstract}

No livro O chiste e suas relações com o inconsciente (1996a), publicada pela primeira vez em 1905, encontra-se a primeira referência de Freud à estética. Ao constatar o pequeno interesse dispensado ao chiste pelos teóricos da estética, Freud opta por estudá-lo pelo viés do cômico, tema privilegiado pela maioria dos especialistas. Entre eles, Kuno Fischer (1889) afirma que o assunto da comicidade é o feio e que, onde este esteja escondido, deve ser revelado pelo cômico. Parte da premissa de que nosso universo espiritual contém uma enormidade de coisas risíveis que podem ser contrastadas. Para este autor, o juízo que produz o contraste cômico é o chiste, "um juízo que joga, (...) assim como a liberdade estética consistiria em abordar as coisas jogando com elas". ${ }^{1}$ (FISCHER apud FREUD, 1996a, p. 12 - destaques nossos). A conduta estética diante de um objeto é singularizada pela condição de que não

1 Todas as citações referentes a FREUD, foram retiradas da edição argentina (Amorrortu ed.) das Obras completas e vertidas para o português.

* Pontifícia Universidade Católica de Minas - PUC Minas. 
lhe demandemos satisfação alguma de nossas necessidades sérias, mas que nos contentemos com gozar em abordá-lo.

O chiste apresenta como propriedade essencial a brevidade. Nele se diz o que se tem a dizer "nem sempre com poucas palavras, mas com um número exíguo delas, palavras que, segundo uma lógica rigorosa ou modos comuns de pensar e falar não bastariam”. (LIPPS apud FREUD, 1996a, p. 15).

Através de técnicas como a condensação, o deslocamento, o uso múltiplo da mesma palavra, o duplo sentido e a representação pelo oposto, o chiste economiza o trabalho psíquico requerido pelo pensamento sério. Disso resulta uma descarga prazerosa evidenciada pelo riso. As técnicas dos chistes são, em si mesmas, fontes de prazer. Os jogos de palavras e o não-sentido (nonsense) dão ênfase à sonoridade e não ao sentido que a palavra encerra. Através deles são restabelecidas antigas liberdades e desfeitas as coerções que a educação intelectual impõe.

As técnicas do chiste são relacionadas ao jogo infantil com as palavras. Quando a criança está aprendendo a manejar o léxico de sua língua materna tem enorme prazer em "experimentar jogando" (GROOS apud FREUD, 1996a, p. 20) com esse material; tece palavras sem ater-se à condição de sentido, a fim de alcançar com elas o efeito prazeroso do ritmo e da rima. Essa maneira de representação, "é puramente estética, descansa só no interior de si, só dentro de si tem seu fim e não cumpre nenhum outro fim vital". (FISCHER apud FREUD, 1996a, p. 90).

Tais considerações aplicam-se aos chamados chistes inocentes, cujo único fim é a obtenção de prazer da própria atividade psíquica, do puro representar estético. Freud, a partir desse ponto, traz à baila os chistes tendenciosos os quais, em virtude de sua tendência, dispõem de fontes de prazer inacessíveis aos chistes inocentes. A tendência, quando hostil, presta-se à agressão, à sátira ou à defesa; quando obscena, está a serviço do desnudamento.

O chiste obsceno, nas palavras de Freud, é muito raramente considerado digno de estudo, "como se certa repugnância tivesse se transferido de seu tema para o fato positivo de sua existência" (FREUD, 1996a, p. 91). O escárnio indecente coloca deliberadamente em evidência, através do dizer, circunstâncias sexuais. Dirige-se a alguém que desperta excitação sexual e em quem se pretende que, ao escutá-lo, seja tomado por igual excitação. É originalmente endereçado à mulher, com o intuito de seduzi-la, tendo como objetivo desnudá-la. O homem talvez conte, nesse modo de abordagem, com um certo exibicionismo presente nela sob a capa do pudor sexual, sendo necessário "que se lhe reserve, através 
do próprio vestuário, uma pequena porta de escape”. (FREUD, 1996a, p. 93).

O escárnio indecente, aceito sem disfarce nos meios vulgares, pode despertar na sociedade refinada, ao invés de excitação sexual, vergonha e embaraço. Sendo assim, nos ambientes onde rege a boa educação ele só pode ser tolerado "sob a condição formal do chiste". (FREUD, 1996a, p. 95). O recurso técnico da alusão, ou seja, a substituição do francamente sexual por algo associado remotamente a ele, permite ao ouvinte reconstruir através da imaginação a obscenidade mais plena e direta. Quanto maior o mal-entendido entre o que é apresentado diretamente pelo escárnio e o que ele evoca no ouvinte, tanto mais fino será o chiste e mais alto poderá conseguir subir à sociedade.

O chiste obsceno, através da técnica alusiva, contorna um obstáculo - a manifestação crua do sexual - extraindo prazer de uma fonte abjeta. Essa fonte ancora-se na sexualidade infantil, perverso-polimorfa, caracterizada pela lassidão das barreiras do pudor, da repugnância e da moralidade. A ação combinada da coerção educativa externa e das defesas internas (os recalcamentos) encarrega-se de solidificar essas barreiras e transformar aquilo que era prazeroso na infância em algo repulsivo e inaceitável na idade adulta.

Freud assinala que, quando o adulto educado ri de um fino chiste obsceno, ele está rindo da mesma coisa que provoca riso no sujeito vulgar que ouve um escárnio indecente. A pessoa refinada, porém, repugna o escárnio indecente e só pode rir "quando o chiste lhe presta socorro". (FREUD, 1996a, p. 95).

$\mathrm{O}$ estudo dos chistes tendenciosos demonstra que, além de extrair prazer de estruturas formais através do jogo linguístico, o chiste também desprende prazer a partir de sua tendência, ao liberar componentes pulsionais inconscientes até então inacessíveis. Por isso Freud, em desacordo com muitos teóricos da estética, sustenta que o chiste não é simplesmente uma subespécie do cômico. Para ele, chiste e comicidade se distinguem sobretudo pela localização psíquica: o chiste é, por assim dizer, "a contribuição feita à comicidade pelo domínio do inconsciente". (FREUD, 1996a, p.197).

Em O criador literário e o fantasear (1996b) Freud estabelece novo debate com a estética. Afirma que a criação, dramática ou literária, é um jogo de importantes consequências, pois muitas coisas que, por serem reais, não trazem gozo podem, contudo, proporcioná-lo como jogo de fantasia; do mesmo modo, muitas excitações que em si são dolorosas podem tornar-se fontes de prazer para os espectadores.

Destaca ainda que, via de regra, envergonhamo-nos de nossas fantasias eróticas e agressivas e, ao reprová-las, as guardamos como nosso segredo mais 
íntimo. O poeta, ao contrário, apresenta-nos seus produtos fantasiosos e, ao fazê-lo, permite que nos deleitemos com eles. Consegue isso através do que Freud situa como sendo a autêntica ars poetica, que consiste na técnica de superar as barreiras que se erguem entre cada eu singular e os outros. Ele não só atenua o caráter pessoal e egoísta de suas fantasias como também "subornanos por meio de um ganho de prazer puramente formal, ou seja, estético, que ele brinda com a figuração de suas fantasias". (FREUD, 1996b, p.135).

Freud denomina "prêmio de estímulo ou prazer preliminar" (FREUD, 1996b, p. 135) a esse gênero de prazer, que é-nos oferecido para possibilitar a liberação de um prazer ainda maior, proveniente de fontes psíquicas mais profundas. Assim, para além do prazer preliminar, o gozo genuíno de uma obra poética deve, segundo Freud, provir da liberação de tensões em nossa alma, em outros termos, do cancelamento de inibições internas cuja fonte situa-se no inconsciente. Ao tocar, por meio do recurso formal, fontes pulsionais antes inacessíveis, o escritor criativo pode oferecer-nos a possibilidade de, dali em diante, gozarmos de nossas próprias fantasias sem remorso ou vergonha.

Freud observa que há no exercício da arte uma atividade que visa a apaziguar desejos sufocados, em primeiro lugar, no próprio artista criador, em segundo, no seu leitor ou espectador. $\mathrm{O}$ artista busca a autoliberação e a leva a outros, que padecem dos mesmos desejos retidos, ao apresentar-lhes sua obra. Figura como realizadas as fantasias de desejo mais pessoais; porém, estas só se convertem em criação artística mediante uma transformação que possa mitigar o caráter ofensivo desses desejos, ocultar sua origem pessoal e observar "regras de beleza que subornem os demais com gratificações de prazer”. (FREUD, 1996e, p. 89). As criações artísticas "servem-se do prazer perceptivo da beleza formal como se esse fosse um prêmio de sedução". (FREUD, 1996j, p. 61).

O caráter sedutor da beleza é destacado por Freud em alguns textos. Em nota de 1915, apensa a Três ensaios sobre a teoria da sexualidade, texto de 1905, o autor afirma que o conceito do belo, embora associado ao encanto, tem sua base no campo da excitação sexual e originalmente significou "aquilo que excita sexualmente". (FREUD, 1996, p. 142). Note-se que o termo alemão Reiz significa tanto estímulo quanto encantos. Conectado a isso, temos o fato paradoxal de que, mesmo que não achemos propriamente "belos" os genitais, sua visão provoca em nós a mais poderosa excitação sexual.

Seguindo essa trilha, Freud, no artigo Sobre a mais generalizada degradação da vida amorosa (1912), enfatiza que a pulsão sexual é composta por vários elementos, entre eles as tendências coprófilas e sádicas, altamente 
prazerosas para a criança. Sendo incompatíveis com a nossa cultura estética, esses componentes são recalcados mas deixam seus traços na vida amorosa do adulto. Segundo o autor, "o excrementício forma com o sexual uma urdidura demasiado íntima e inseparável, sendo que a posição dos genitais - inter urinas et faeces - segue sendo o fator decisivo e imutável". (FREUD, 1996c, p.182-3). Além disso, continua Freud, os próprios genitais não acompanham o desenvolvimento em direção à beleza das formas do ser humano e conservam um caráter animal.

Pois bem, se nos meios sociais refinados o processo educacional aparenta ter ido longe demais na sufocação da escatologia, esta ainda sobrevive na cultura e costumes populares, na feitiçaria e, inclusive, no culto e na arte de curar, conforme Freud assinala em seu Prólogo à tradução alemã de J. G. Bourke, Scatologic rites of all nations (1913).

Vale ainda lembrar o ensaio Sonhos no folclore (1958 [1911]), que traz a seguinte epígrafe: "os soberanos excelsos deixam de lado os poemas carentes de encanto". (FREUD, 1996d, p. 183). Esse ensaio apresenta alguns sonhos escatológicos colhidos do folclore de vários povos e é concluído com duas observações:

Por um lado, a frequente modalidade repelente do material folclórico, por suja e indecorosa que seja, não deve fazer com que desistamos de buscar neste material valiosas confirmações das concepções psicanalíticas. [...] Por outro, faz-se uma injustiça ao povo quando se supõe que cultiva esse modo de entretenimento só para satisfazer as mais grosseiras concupiscências. Pelo contrário, parece que por trás dessas feias fachadas escondem-se reações a impressões vitais que devem ser levadas a sério e até são tristes, reações a que o homem do povo está pronto a entregar-se desde que se façam acompanhar por um ganho de prazer grosseiro (FREUD, 1996d, p. 205).

Agregue-se a isso as observações de Freud em $\mathbf{O}$ mal-estar na cultura (1930) sobre a alegria do artista no ato de criar e corporificar os produtos de sua fantasia. São atividades mais finas e "superiores" que, no entanto, "não comovem nossa corporalidade”. (FREUD, 1996k, p. 79). Sua intensidade revelase tênue quando comparada à que se origina da satisfação de moções pulsionais mais grosseiras e primárias. A suave narcose que a arte provoca não faz mais que produzir um afastamento provisório das exigências da vida; não é o bastante intensa "para fazer esquecer uma miséria real". (FREUD, 1996k, p. 80).

A felicidade pode ser buscada no gozo da beleza e essa atitude estética 
consegue ressarcir muitas coisas mas oferece escassa proteção contra o sofrimento real. A ciência estética indaga as condições sob as quais se sente o belo; contudo - ressalta Freud - não pode trazer qualquer esclarecimento sobre a natureza e origem da beleza, embora recubra essa falha pelo uso de palavras altissonantes e de magro conteúdo. Por desdita, "também a psicanálise quase nada sabe dizer sobre a beleza”. (FREUD, 1996k, p. 83).

O tom dessas passagens é pesado e só faz realçar a falência dos inevitáveis recursos culturais que acenam com promessas de felicidade. O que se eleva aqui é o nosso desamparo e a inexorabilidade da morte. O campo aberto por Freud não mais se situa na alternância entre o prazer estético advindo da beleza formal e aquele exigido pela satisfação pulsional grosseira. Trata-se agora do embate entre vida e morte.

Em De guerra e morte: considerações atuais (1915) Freud é categórico ao afirmar que ninguém acredita em sua própria morte ou - o que vem a ser o mesmo - no inconsciente cada um de nós está convencido de sua imortalidade. (FREUD, 1996g, p. 290).

O homem primitivo comportava-se de modo contraditório diante da morte. A morte do outro - um desconhecido ou inimigo - era para ele justa e significava a eliminação do que era odiado por ser estrangeiro. Sua própria morte era, todavia, tão irreal e inimaginável quanto ainda é hoje para cada um de nós. Entretanto, quando viu morrer um dos seus, teve que aprender, na sua dor, que ele também poderia morrer. Não lhe era mais possível manter a morte a distância, já que a havia provado através do luto pelo próximo.

Diante da morte do próximo enterramos com ele nossas esperanças e alegrias, recusando-nos a substituir o que perdemos. Desvalidos, tentamos encontrar na literatura e no teatro substitutos para as perdas da vida. No reino da ficção "achamos a pluralidade de vidas de que necessitamos". (FREUD, 1996g, p. 292). Identificados com o herói da peça podemos morrer com ele várias vezes e, ao mesmo tempo, sobreviver a ele outras tantas.

Na tragédia (no alemão Trauerspiel é, literalmente, jogo de luto) o cenário montado pelo poeta "não poupa ao espectador as mais dolorosas impressões, não obstante o que pode senti-las como um elevado gozo". (FREUD, 1996i, p. 17). Afinal, por mais que a plateia sofra, quem morre é o herói - a um só tempo amado, admirado e invejado - para logo renascer, resplandecente, do seu sofrimento eterno.

Para Lacan, a tragédia é a evocação do desejo de morte escondido atrás da calamidade em torno da qual gira o destino do herói trágico; a beleza cumpre 
nela a função de "miragem fundamental, pela qual o ser perecível e frágil é sustentado em sua busca de perenidade, que é a sua aspiração fundamental". (LACAN, 1992, p. 130). A verdadeira barreira que detém o sujeito diante do campo da destruição absoluta "é o fenômeno estético propriamente dito uma vez que é identificável com a experiência do belo”. (LACAN, 1988, p. 265).

Freud, em O sinistro (1919), observa que o psicanalista raramente é incentivado a empreender investigações estéticas, seja quando conceba este campo como doutrina do belo, seja quando o considere como ciência das qualidades de nosso sentir. Segundo o autor, a estética geralmente evita ocupar-se daquilo que contrasta com o belo, ou seja, do repulsivo, do penoso e do aterrador.

Através da pesquisa linguística Freud verifica que Unheimlich (sinistro, estranho, inquietante) coincide com o seu oposto Heimlich (doméstico, familiar), sendo o sinistro uma categoria do assustador que remonta "ao consabido de velho e há muito familiar". (FREUD, 1996h, p. 220). Como entender que algo tão familiar se constitua como sinistro e aterrorizante?

Voltando ao processo de luto, pode-se considerar que, mesmo admitindo a morte física de um dos nossos, tendemos a perenizar sua vida no âmbito espiritual. Se levarmos em conta que todo próximo guarda uma certa estranheza e que toda tendência amorosa contém um sedimento de ódio torna-se compreensível que os espíritos dos mortos amados possam transformar-se em sinistros demônios. Assim, "o morto passa a ser inimigo do sobrevivente e procura levá-lo consigo para que o acompanhe em sua nova existência". (FREUD, 1996h, p. 242).

Contudo, "o medo com seus fantasmas já é uma defesa localizável, uma proteção contra algo que está para além, e que é precisamente o que não sabemos". (LACAN, 1988, p. 283). O sinistro, por mais aterrador que seja, nos conforta. Revidando ao dito "antes só do que mal acompanhado" diríamos: "antes mal acompanhado, mesmo que por seus fantasmas, do que só".

Ao término de $\mathbf{O}$ sinistro Freud faz referência à solidão, ao silêncio e à escuridão .Poder-se-ia dizer que fora do âmbito das qualidades estéticas - que marcam o campo que vai do mais belo ao mais repulsivo, do mais apaziguador ao mais aterrador, do mais prazeroso ao mais desprazeroso - há algo da ordem de uma indiferença estética, assim ilustrada em Além do princípio do prazer:

... todo movimento psicofísico que ultrapasse o umbral da consciência é afetado por prazer na medida em que se aproxima, mais além de certa fronteira, da estabilidade plena, e afetado por desprazer na medida em que mais além de certa fronteira se desvie daquela estabilidade, existindo entre as duas fronteiras, 
que devem ser caracterizados como umbrais qualitativos de prazer e desprazer, uma certa margem de indiferença estética... (FECHNER, 1873 apud FREUD, 1996i, p. 8).

Ao constatar que a estética se ocupa sobretudo do belo e das qualidades do sentir, Freud demanda, de modo enigmático, "uma estética de inspiração econômica" (FREUD, 1996i, p. 17) que, supomos nós, seja despojada de qualquer qualidade. Mas como apreender aquilo que não apresenta qualidade sensível, como nomear o real da solidão, do silêncio e da escuridão? Nesse ponto há morte e tanto a estética quanto a psicanálise nada terão a dizer.

\begin{abstract}
This article will consider some formulations done by Sigmund Freud about aesthetics and art. Understanding aesthetics as being the science of beauty, Freud creates a new trend related to "oddness". This theme often provokes repulsiveness, fright and horror creating a necessity of art appreciation other than the ones perceived in harmony and beauty..
\end{abstract}

Key words: Sigmund Freud. Oddness. Aesthetics. Art.

Referências

FREUD, Sigmund (1905). Tres ensayos de teoría sexual. Obras completas. Buenos Aires: Amorrortu, 1996, v. 7.

FREUD, Sigmund (1905). El chiste y su relación con lo inconciente. Obras completas. Buenos Aires: Amorrortu, 1996a, v. 8.

FREUD, Sigmund (1908). El creador literario y el fantaseo. Obras completas. Buenos Aires: Amorrortu, 1996b, v. 9.

FREUD, Sigmund (1912). Sobre la más generalizada degradación de la vida amorosa. Obras completas. Buenos Aires: Amorrortu, 1996c, v. 11.

FREUD, Sigmund (1958[1911]). Sueños en el folklore. Obras completas. Buenos Aires: Amorrortu, 1996d, v. 12. 
FREUD, Sigmund (1913). Prólogo a la traducción al alemán de J. G. Bourke, Scalogic rites of all nations. Obras completas. Buenos Aires: Amorrortu, 1996e, v.12.

FREUD, Sigmund (1913). El interés por el psicoanálisis. Obras completas. Buenos Aires: Amorrortu, 1996f, v. 13.

FREUD, Sigmund (1915). De guerra y muerte. Temas de actualidad. Obras completas. Buenos Aires: Amorrortu, 1996g, v. 14.

FREUD, Sigmund (1919). Lo ominoso. Obras completas. Buenos Aires: Amorrortu, 1996h, v. 17.

FREUD, Sigmund (1920). Más allá del principio de placer. Obras completas. Buenos Aires: Amorrortu, 1996i, v. 18.

FREUD, Sigmund (1925). Presentación autobiográfica. Obras completas. Buenos Aires: Amorrortu, 1996j, v. 20.

FREUD, Sigmund (1930). El malestar en la cultura. Obras completas. Buenos Aires: Amorrortu, 1996k, v. 21.

LACAN, Jacques. O seminário, livro 7: a ética da psicanálise. Rio de Janeiro: Jorge Zahar, 1988.

LACAN, Jacques. O seminário, livro 8: a transferência. Rio de Janeiro: Jorge Zahar, 1992. 
RESENHAS 